\title{
British Military Hospital Dharan: Surgical Experience 1985-86
}

\author{
Lt Col J M Ryan, FRCS, RAMC \\ Consultant Surgeon \\ ${ }^{*}$ British Military Hospital Dharan, HQ Brig Nepal, BFPO 4
}

SUMMARY: The clinical experience of an Army Surgeon in a Military Hospital in East Nepal is discussed. The trul $\overrightarrow{\vec{p}}$ general nature of the work load is highlighted and the need for a broad based general training in surgery for such a task. is well illustrated. A high degree of inter-disciplinary co-operation was experienced and was indeed essential for good clinical practice. The health problems of a developing country are glimpsed. The severe limitations imposed on clinica $\bar{p}$ practice as a consequence of limited facilities are particularly noteworthy.

\section{Introduction}

British Military Hospital Dharan is situated in the foothills of the Himalayas in East Nepal. Close to the hill region where recruitment of Gurkha soldiers takes place twice yearly, it is well placed to provide medical care for them and for ex-soldiers, pensioners and their families on their return home following military service. Nevertheless some of these families are still many days', and in some cases, up to 2 weeks', walk from the hospital.

The hospital, purpose-built and modern, has 70 beds, 10 cots, 5 maternity beds and 20 hostel spaces. Medical care is provided for local British Servicemen and their families, British Gurkha Servicemen and pensioners. Large numbers of local people are also cared for when beds and resources allow. In addition, the hospital has become a reference centre for doctors and nurses employed in the region who work for such diverse agencies as the Overseas Development Agency, the Save The Children Fund and the Britain Nepal Medical Trust.

\section{Background}

BMH Dharan owes its existence to the Brigade of Gurkhas, an integral unit of the British Army. The Brigade traces its origins to 1815 when the first Regiments were raised following a series of wars between Great Britain and Nepal. Such was the admiration of the British for the hardy hill men of Nepal, that recruitment began immediately following the treaty ending the wars. Following the Grant of Indian Independence in 1947 Britain retained 4 of the original 10 Regiments. These 4 Regiments and their supporting units form the British Brigade of Gurkhas.

Prior to 1953 , recruitment of Gurkhas soldiers required potential recruits to travel to various British Gurkhas depots in India. Following a request from India to close these, and with the permission of the Nepalese Government, Gurkha recruitment depots were opened in Nepal. Dharan Cantonment, the largest, opened in 1960. Thus ended a long association between British Gurkhas and India; the medical association ended with

*Now Consultant Surgeon, CDE, Porton Down, Salisbury, Wilts and Princess Alexandra Hospital, RAF Wroughton. the closure of the Medical Reception Station at Ghusre The British Military Hospital at Dharan opened its? doors at the end of October $1960^{1}$.

\section{Facilities and Staffing}

The hospital has male and female wards for urgent medical and surgical problems which include? osteomyelitis, neglected burns, TB in its many forms $\underset{\perp}{\omega}$ untreated injuries (often with associated compoundb fractures) and patients with malignant disease. A small $\vec{b}$ children's ward is attached to the female ward and le rov 10 cots. A 5 bay maternity unit is also maintained. $4 A$ 음 pulmonary tuberculosis ward and a minimal care wandare available for patients on long term treatment chronic conditions. A Medical Dharmasla or Hostebis: situated in the cantonment grounds providing food a shelter for patients on long term treatment, but who are mobile and capable of self care.

A modern operating theatre with 2 tables is in use. laboratory, X-ray department and Dispensary are rim by senior technicians RAMC. X-ray reporting is responsibility of individual clinicians, the RAMC radiographer providing a screening and ultrasounh service. A well equipped Dental department isD maintained by a locally employed dental technician supported, twice yearly, by visits from service dentists? from Hong Kong. A REME section provides an electro 3 medical service and also runs a very efficient limb fitting service using local resources and artificial limbs discarded by the DHSS(UK).

Medical, Surgical, TB, Fracture and Antenatal clinics are held in a large outpatient department. Two generaR practitioners run a "Villagers' Clinic" for non-entitledচ local people, which, with hundreds of people attending is one of the highlights of the hospital's day.

Senior Medical and Nursing staff are British and from the Services. A General Physician, General Surgeon and an Anaesthetist run their departments singlehanded but have Nepali Medical Officer Assistants and 0 from time to time, medical students on elective periods? at their disposal. A Matron and 4 QARANC Nursingo Sisters supervise all aspects of nursing care including. nurse training, and also run a very busy obstetrics services which includes a domiciliary element. (Matron and 2 of the 4 nursing sisters are always midwives). Two locallyN్ట 
employed general practitioners are responsible for primary care. Specialists in Obstetrics and Gynaecology, Orthopaedics and ENT surgery visit from UK and Hong Kong on a regular basis.

All hospital departments have locally trained and competent Nepali staff who fill most of the nursing and technical posts. Among these are radiographers, dispensers, physiotherapists, and laboratory and operating theatre technicians. Many of these have been on the staff since 1960 and are very experienced. It is noteworthy that the valuable Medical Officer Assistant grade has no counterpart in British medical practice.

The hospital has a unique Administrative Officer, $\mathrm{Mr}$ Ranjit Singh Rai, MBE. An ex-Gurkha soldier, he has been Administrative Officer since the hospital's opening and played a major role in its conception and construction. His encyclopaediac knowledge of all matters relating to the hospital and his unfailing kindness and friendship has made him an indispensable ally to countless clinicians over the last 25 years.

\section{Clinical Material and Case Load}

With no equivalent facility in the region, great demands are placed on the hospital. A local regional hospital exists but it was poorly staffed, and conditions there were described by an eminent British Surgeon during a visit in 1982, as mindful of Scutari before Florence Nightingale ${ }^{2}$.

The wards and outpatients of $\mathrm{BMH}$ Dharan were crowded with patients, and the extent and severity of their diseases evoked images of the wards of London teaching hospitals in the nineteenth century. Sitting in outpatients clinics was like opening the pages of an ancient textbook of pathology.

Many patients presented with florid and untreated disease - neglected burns, complex fractures, TB and pyogenic osteomyelitis, disseminated malignancies and untreated congenital malformations. Patients trekked for days and sometimes weeks to seek treatment. Some were beyond help, but all presented surgical challenges.

Crisis management was routine. The working week started with an early morning ward round to clear beds. This was followed by a surgical clinic lasting all day. Referral to this clinic was from Medical Officer Assistants who had earlier sorted potential patients in a "vetting area" close to the hospital entrance. This was, in effect "triage", and was essential to the smooth running of the hospital ${ }^{3}$. Referral was also from hospital colleagues and from medical workers in the hills working for the Save the Children Fund, Britain Nepal Medical Trust and the Overseas Development Agency.

Clinic size varied with between 60 and 80 new patients presenting, of whom most required urgent treatment. From these Monday clinics, an operating list was compiled. It will be appreciated that clerking and preoperative investigations had to be kept to a minimum. Blood for transfusion was available only if relatives donated, and most were unwilling to do so. The operating list for the following day, Tuesday, was partly planned but had to be flexible in that additions were invariably made as the day progressed. Wednesday was reserved for post-operative follow up, $\mathrm{X}$ ray reporting and administration. Thursday and Friday were a repetition of Monday and Tuesday, and Saturday was set aside for a combined teaching round involving all hospital staff and visiting doctors and nurses from the Save The Children Fund, Britain Nepal Medical Trust and other agencies.

The case load was in part related to what individuals and available resources could bear. Inevitably follow up was haphazard. It is not surprising that these aspects affected the type and number of patients selected for admission and treatment.

During the author's tenure from October 1985 to November 1986,3899 patients were seen in clinics. From this group, 1426 patients were operated on, either as inpatients or outpatients.

\section{Analysis of Case Load}

The lack of national medical and health statistics make discussion on disease prevalence impossible. The national incidence for individual diseases can only be guessed. The case load was very general and all specialities were represented.

Orthopaedic and trauma problems could have filled all available beds continuously (Table 1 ). Rigid selection of cases to avoid long term bed occupancy was practised, and patients with an antitipated quick good result were preferred. Gross osteomyelitis of multiple sites was a constant problem with regard to management and length of stay. A conservative approach was adopted and only ill children with an acute exacerbation of their disease were admitted (Fig 1). On the other hand, closed and operative treatment of paediatric fractures, and operative management of congenital abnormalities such as talipes was much practised, and proved very rewarding (Fig 2).

The abdominal cases were varied and differed from British practice in many respects (Table 2). In East Nepal, large bowel malignancy appeared to be very rare, only a handful of cases presenting to the hospital in the year under discussion. Abdominal tuberculosis, usually presenting with ascites and incipient obstruction, was common, but settled on conservative measures, and such cases were managed by the physicians. The high incidence of biliary disease in the practice was noteworthy. Invariably the disease affected obese pensioners' wives and was probably related to their relatively affluent lifestyle. Hepatic and renal hydatid disease was encountered frequently. One nonchalant individual was noticed in clinic as he casually winkled a daughter cyst from his external urinary meatus. He later tried to present us with a matchbox full of daughter cysts! Duodenal ulcer disease was rare, our only perforation presenting in a European woman who arrived in a very ill state 24 hours after onset. Gastric 
Table 1

Operations - Orthopaedies and Trauma

Manipulation under anaesthetic-Fractures and Dislocations

Wound Toilet-Soft Tissue and Compound Fractures

Operative Reduction of Fractures

Removal of Internal Fixation Devices

Amputations-All

Above Knee-6, Below Knee- 5

UL-5, Symes-1, Digit 9

Sequestrectomy and Sauccrisation

Joint Toilet-Septic Arthritis

Revision Amputation Stumps

\section{3}

73

35

29

26

21

15

9
Lengthen Tendo Achilles and Soft Tissue

Release

Potts and Psoas Absecesses (Spinal

Tuberculosis)

Application of External Fixator

Repair Tendo Achilles

Meniscectomy

Application of Skull Tongs

Elevation Depressed Fracture Skull

Ventriculo-Peritoneal Shunt for Hydrocephalus
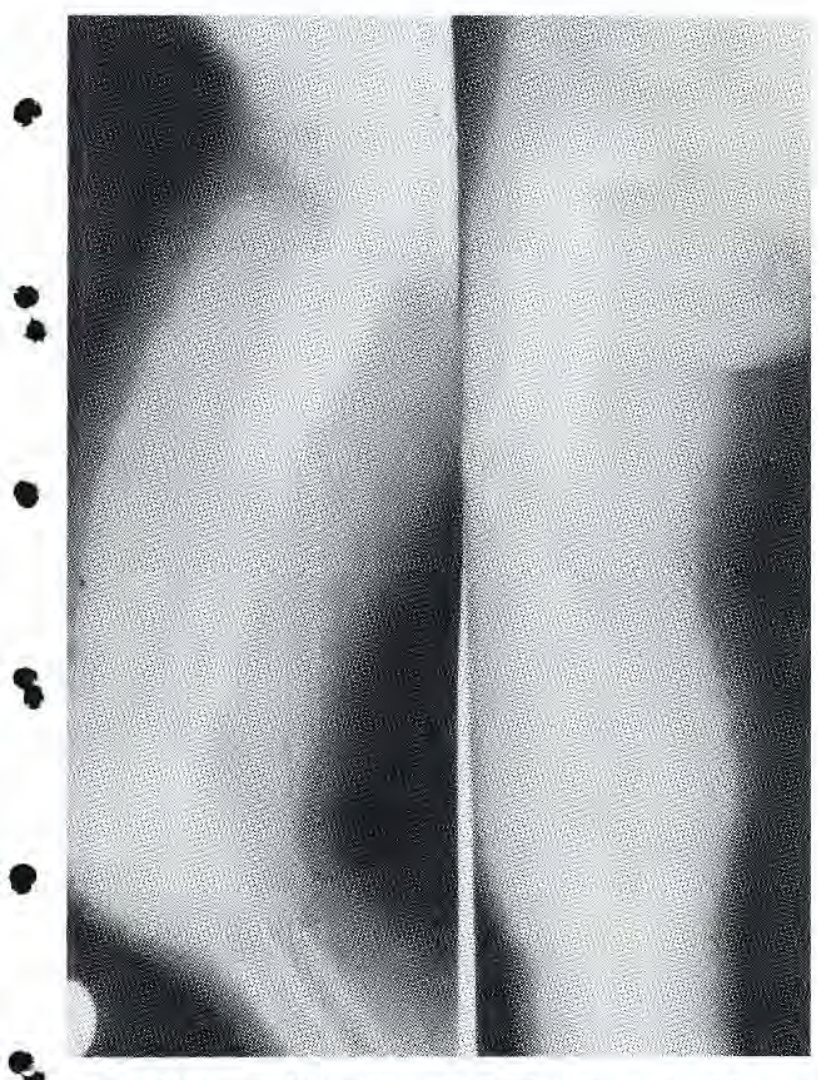

Fig 1. Osteomyelitis with pathological fracture of femur

\section{8

ulcers and gastric cancers were common and were picked up at most endoscopy sessions. This service was provided by both physician and surgeon on different days, making it virtually available on demand.

This high incidence of positive findings was unusual and will be the subject of a future paper by both

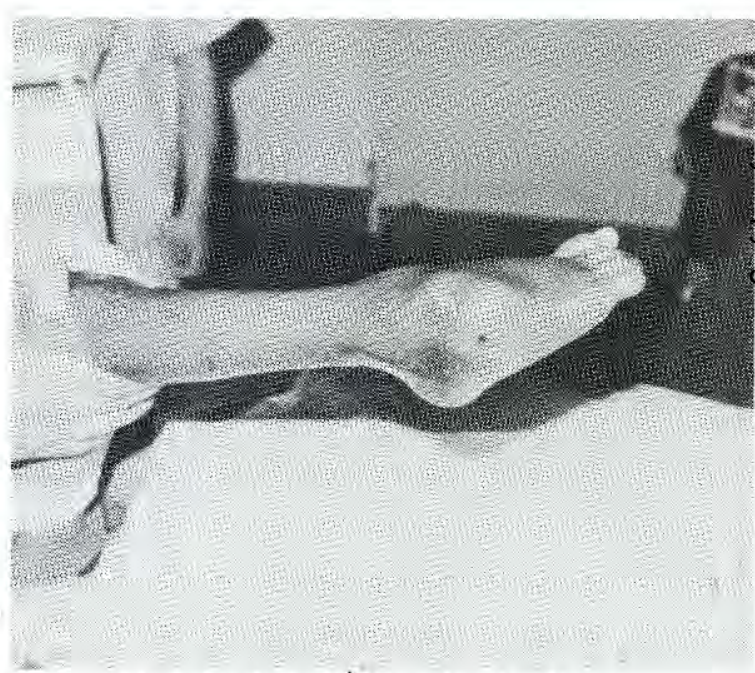

Fig 2. Neglected Talipes Equino Varus 
Table 2

Operations - Abdominal Wall and Gastro-Enterology

Upper Gastrointestinal Tract Endoscopy

\pm Biopsy (Surgical Figures only)

Herniotomy

Sigmoidoscopy \pm Biopsy

Cholectystectomy and Peroperative

Cholangiogram

Laparotomy and Biopsy only

Cirrhosis - 16, Inoperable Malignancy - 10

Lords Manual Dilation of Anus

Herniorrhaphy

Partial Gastrectomy - Gastric Ulcer

Gastrectomy-All types - Cancer

Hepatic Hydatid Cystectomy

Lay Open Fistula in ano

Snare Rectal Polyp

Milligan Morgan Haemorrhoidectomy

Closure Loop Colostomy

Transverse Loop Colostomy - Perforation

- Tuberculosis

Drain Amoebic Liver Abscess

Transverse Colectomy
66

52

47

40

26

25

22

7

6

5
Incisional Hernia Repair

Highly Selective Vagotomy

Oversew Perforation - Duodenal Ulcer

Cholecystectomy and Explore Common Bile Duct

Right Hemicolectomy

Burst Abdomen

Truncal Vagotomy and Gastroenterostomy

Ramstedt's Plyoromyotomy

Triple Bypass - Carinoma Pancreas

Partial Hepatectomy

Laparotomy - Division Adhesion - Tuberculosis

Laparotomy-Faecal Fistula-Strangulated Hernia

Laparotomy - Gunshot Wound - Small Bowel

+ Mesentery

3 Laporotomy Repair Ureteric Injury

Anterior Resection

Ileostomy and Mucus Fistula

Closure Ileostomy

Total 337 clinicians. Endoscopy was practised without sedation and was well tolerated. This approach was not the result of callousness but of necessity; the patients required their full senses to trek to their homes, often a hazardous undertaking.

Urological practice (Table 3) was remarkable for the number of children presenting with bladder stones, often large and multiple. The eliciting of a history of strangury with relief on lying down was invariably diagnostic and was recognised by local people. The relative absence of an older age group affected our practice, and very few patients presented with prostatic disease. Urethral strictures were common, usually presenting with retention. Most responded to regular urethral dilatation. We noted that many traditional healers practised this art and, indeed, many other procedures which brought us into conflict with them from time to time ${ }^{4}$.

Advanced carcinoma of penis often presented at a late stage with patients with severe pain and bleeding, and with an unforgettable smell.
Skin and soft tissue conditions formed a significant group (Table 4). Abscesses, particularly common during the summer monsoon, were unusual by virtue of size, multiplicity of sites and amounts of pus drained, up to $500 \mathrm{ml}$ being common. Tropical pyomyositis, rarely seen in Western practice, accounted for $30 \%$ of all abscesses; the condition used to be difficult to diagnose as the pus was deep to the deep fascia, but ultrasound has revolutionised the diagnosis and was highly accurate in localising pus. Breast abscesses in lactating mothers often presented very late with total destruction of breast tissue and causing serious social consequences amongst a population dependent upon breast feeding. Living conditions resulted in frequent and severe burns and scalds to children, usually presenting late with hideous deformity. An almost universal keloid tendency added to their misery and made management difficult and prolonged.

The surgery of cleft lip and palate was particularly rewarding (Fig 3). The hospital has gained a reputation over the last 25 years as a centre for the repair of these 
Table 3

Operations - Urological Surgery

Urethro-Cystoscopy-Dilatation - Biopsy

Cystolithotomy

Jaboulay

Wuscheria Bancrofti-3

Circumcision

Pyelolithotomy

Retropubic Prostatectomy

Hypospadas Repair

Orchidectomy-Infection

Ureterolithotomy
$56 \quad$ Nephrectomy

Pyonephrosis-1, Hydatid -1, Wilm's Tumour-1

16 Radical Amputation of Penis and Castration

16 Urethrolithotomy-Children

$\left.\begin{array}{ll}9 & \text { Episadas Repair } \\ 5 & \text { Closure Bladder Extrophy }\end{array}\right]$-Same Patient

5 Amputation Penis

4 Orchidopexy

4 Urinary Diversion - Ileal Conduit Spinal Cord Tumour - 1, Carincoma Uterus - 1

$4 \quad$ Vasectomy

Table 4

Operations - Skin, Soft Tissue and Plastic Surgery

Abscesses - All

Simple-52, Pyomositis-36, Breast-24

Split Skin Grafts - including Meshing

- Excision Simple Cysts - All

Millard Repair Cleft Lip

Release Contractures

Kilner/Wardill and Veau Repair Cleft Palate

Excision of Rodent Ulcers and Epitheliomata
112

Breast Biopsies

60 Revision of Scars

52 Excision Keloid and Steroid Injection

32 Release Syndactyl Fingers

25 Varicose Vein Surgery

20 Toilet Mastectomy

15 Advancement Rotation Flap

Total 341

conditions. All age groups were represented and the whole range of severity was seen from unilateral cleft lip alone to complete bilateral clefts of lip, alveolus and both palates. As a general rule a Millard advancement rotation flap was used for all lip repairs and presented no problems. Palate repair did present difficulties both technically and with regard to follow up. No prosthetic service was available. Palate repairs were after the fashion of Kilner and Wardill for soft palates, and Veau for hard palate defects. It is sad to relate that most palateo defects did not present until late childhood by which time nasal speech and recurrent ear infection were wello established. Nevertheless repair of these defects has? provided immense satisfaction to many surgeons ando patients over the years.

One of the commonest procedures performed ato Dharan was split skin grafting. A meshing device wasn essential due to the extent of many of the defects causedN 


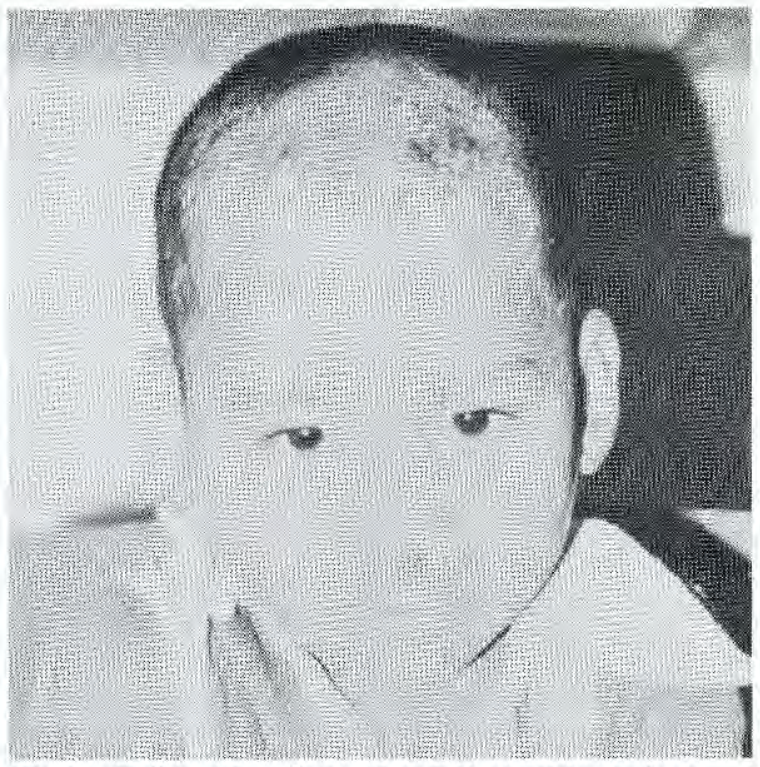

Fig 3a. Child with unilateral cleft lip (and imperigo)

by burns and serious trauma. Skin cancers were noteworthy by virtue of their extent (Fig 4). Almost all were squamous cell carinomas and responded well to wide excision and grafting. Carcinoma of breast was unusual in that only 3 cases were seen, all presented late with chest wall involvement and in great distress. It would be interesting to know the true incidence of this disease in Nepal.

Obstetrics and Gynaecology, not usually the domain of the general surgeon, provided some interesting

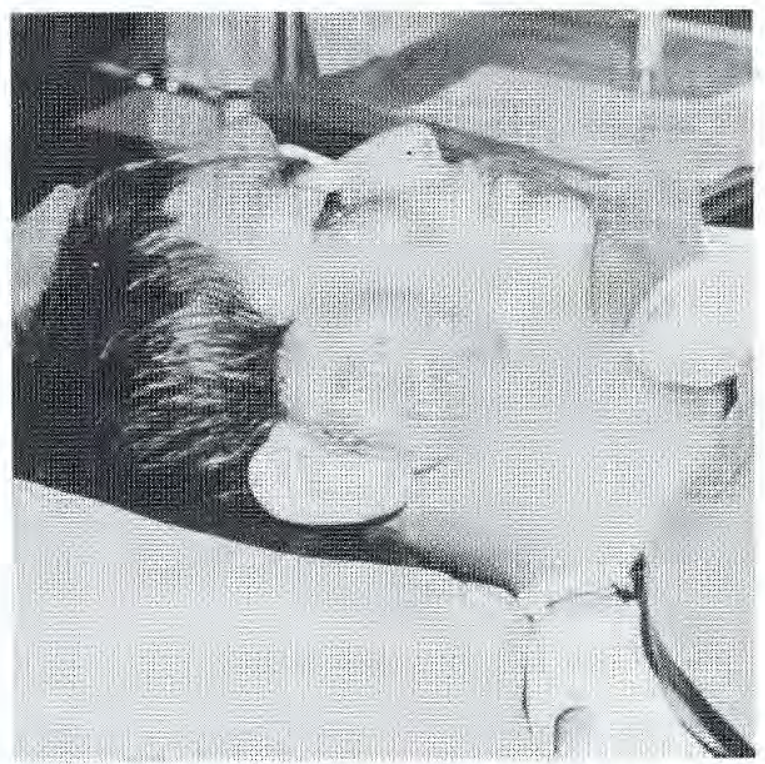

Fig 4. Keratinising squamous cell carinoma

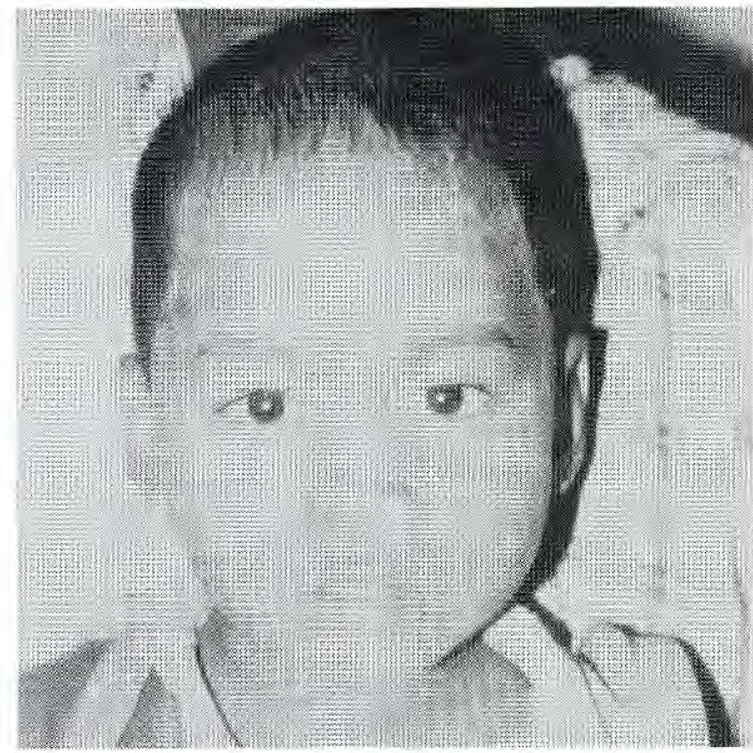

Fig 3b. Same child after Millard Repair

challenges. Three midwives ran this department competently, involving the surgeon only when specific procedures were called for such as Caesarean section or ovarian cystectomy (Table 5). Ovarian cystectomy differed from normal practice by virtue of cyst size - 10$15 \mathrm{~kg}$ on average (Fig 5). Complex gynaecological problems were held over for review by the visiting obstetrician and gynaecologist on his twice ycarly visits.

Thoracic problems presenting to the surgeon were few and usually involved bronchoscopy and biopsy (Table 6). Late disease - TB or carcinoma or both - was the usual finding. Carcinoma of the oesophagus presented difficulties. Three oesophagectomies were carried out but proved very costly and time consuming and involved too many nursing staff in the immediate postoperative period,

Colloid goitre was endemic, but few patients presented, most tolerating their often huge goitres with equanimity. The local belief that goitres contained gold may also have had some effect on attendance. Those patients who did present for thyroid surgery had symptomatic multinodular goitres or other tumours including an enormous undifferentiated tumour of neuroendocrine origin. Only 2 parotidectomies were carried out; these were for a pleomorphic adenoma in a 12 year old girl, and an acinous cell tumour in an old man (Table 7).

Ear, nose, throat and oral surgery, and unclassified operations are listed in Tables 8 and 9 respectively. Carcinoma of tongue and nasopharynx generally presented late with the patient distressed and beyond help; opiates were administered liberally. Entitled pensioners were referred to the North Indian University Medical School at Patna, 100 miles south of Dharan, for 
Table 5

Operations - Obstetrics and Gynaecology

Ovarian Cystectomy

\section{Caesarean}

Dilatation and Curettage

Total Abdominal Hysterectomy

Pomeroy Sterilisation

Evacuation of Retained Products of Conception

\section{2}

20

12

5

4

4
Manual Removal Placenta

Anterior Repair

Posterior Repair

Closure of Vesico-Vaginal Fistula

Closure of Recto-Vaginal Fistula

Salpingo-Oopherectomy-Pyosalpinx

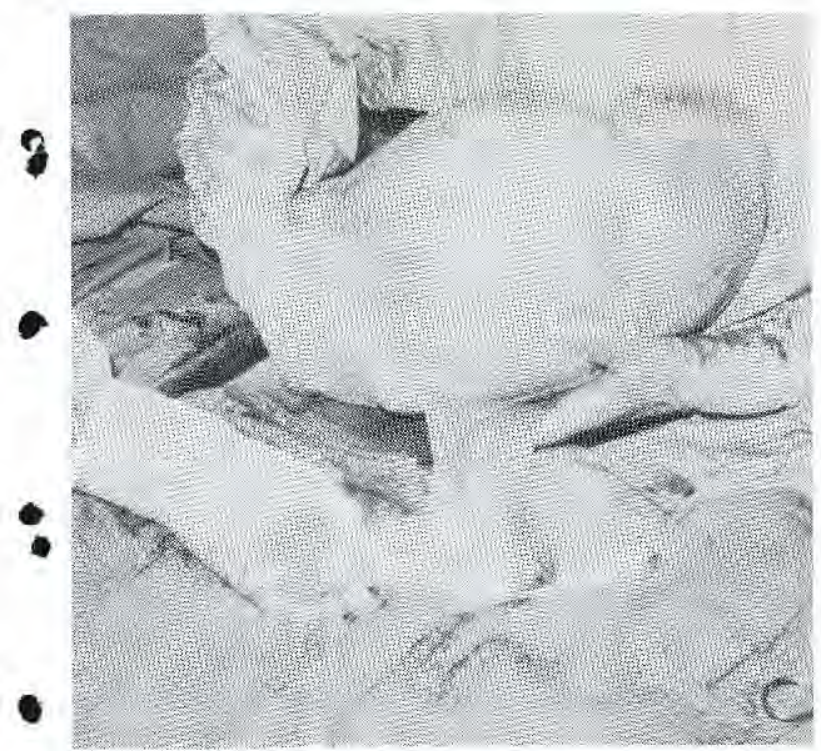

Fig 5 . One of bilateral ovarian cysts

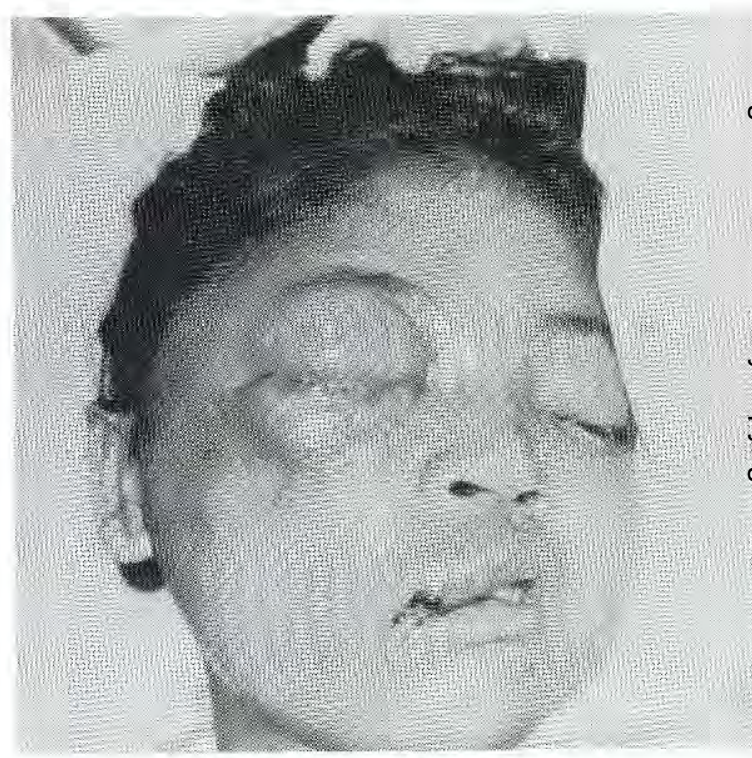

Fig 6. Cavernous sinus thrombosis

Table 6

Operations - Thoracic Surgery

Bronchoscopy + Biopsy

Thoracoplasy - Drain Empyema
20)

4 Oesophagectomy

Trans-Thoracic-2, Trans-Hiatal-1 
Table 7

Operations - Endocrine, Exorcrine and Lymph Nodes

\begin{tabular}{lcl}
\hline Lymph Node Biopsy & 36 & Superficial Parotidectomy \\
Thyroidectomy & 10 & Submandibular Gland excision \\
Partial-9, Total-1 & 5 & \\
$\begin{array}{l}\text { Block Dissection } \\
\text { Cervical-3, Inguinal-2 }\end{array}$ & &
\end{tabular}

Total 55

consideration of radiotherapy and chemotherapy. This Institute gave generously and freely of its time to those of our patients fortunate enough to reach it. Dharan, like all hospitals, produced its share of the unusual and odd during the year under review. The following two paragraphs give some illustrations.

One elderly man presented with an upper limb replaced by a malignant histiocytoma. A 7 year old boy was seen with an enormous tumour invading his scalp and eroding his skull vault at numerous sites, subsequently histology revealing a diagnosis of Histicytosis $X$. A one year old baby present in extremis having virtually exsanguinated from an infantile fibrosarcoma replacing his hand. Cavernous sinus thrombosis was seen in a young woman who recovered after a very stormy course (Fig 6).
Wild animal attacks still occur sporadically. A 12 year old was seen with half his face avulsed following an attack by a Himalayan black bear. Finally an elderly man appeared having been trampled by a herd of elephants; an old wartime amputee, he could not get out of the way quickly enough.

\section{Postscript}

A one year tour of duty as a surgeon in Nepal provided wide-ranging clinical problems and unique experience but this was tempered by limited resources. It was tempting to treat children in preference to other groups. They were numerous, and a delight to treat, and they tolerated surgery well, mobilised quickly and allowed a very rapid turnover.

Table 8

Operations - Ear, Nose, Throat and Oral Surgery

Biopsy Carinoma Tongue - All inoperable

Biopsy Nasal Space for Carinoma

Tracheostomy

Excision of Branchial Cyst
3 Maxillectomy

3 Simple Mastoidectomy

3 Dental Extraction

1

Total 13

Table 9

Operations - Unclassified

Wide excision of undifferentiated

Carinoma of Neck

Excision of Histocytosis X of Scalp

Excision of Schwannoma Median Nerve

Cut back procedure for Low Imperforate Anus
$1 \quad$ Amputation for Infantile Fibrosarcoma-Hand

1 Intra-Abdominal Neurofibroma

1 Amputation for Vascular Hamartomatous Lesion of whole leg

2 Bear Bite-Plastic Repair Face 
Follow up and surgical audit presented problems; so many patients who had trekked for days or weeks to reach help were reluctant to return simply for review. Patients needing multiple procedures and those on long term treatment were encouraged to stay in the Dharmasala until completion of treatment. For young adult males, who had to return to their small farms and livestock, this was rarely possible. Factors such as these affected acceptance for treatment in the first instance, and caused distress.

It is obvious that a surgeon cannot work in isolation. Working in Dharan required a high degree of cooperation between colleagues and this was a feature of clinical life. The consultant physician during my tour was Lieutenant Colonel Guy Ratcliffe RAMC who was also Senior Medical Officer and Commanding Officer. An old Gurkha and Nepal hand, his guidance, clinical advice and friendship were greatly appreciated, and made working in Dharan a continuing pleasure.

Two anaesthetists, not including leave reliefs, graced Dharan during the period of this review - Major Nicholas Strowbridge RAMC and Colonel Tony Booth L/RAMC. Both provided an excellent anaesthetic service and involved themselves in all aspects of patient care. It is to be noted that the resident anaesthetist, when not involved in theatre, acts as doctor to the hospital and cantonment staff and their families. Botlk were also adept at surgery and, during busy periods 3 gave invaluable help by treating many patients on the operating list.

In conclusion, any surgeon with a Nepal tour in prospect would be well advised to acquaint himself with? those areas of clinical surgery not usually dealt with by $a \frac{\vec{s}}{\vec{s}}$ general surgeon in Western practice, includingo gynaecology, obstetrics, general orthopaedics and the surgery of cleft lip and palate.

\section{Acknowledgement}

The author wishes to express his thanks to $\mathrm{Mrs}^{\text {है }}$ Cynthia Hughes who kindly typed the manuscript.

\section{REFERENCES}

1. LANGLANDS A M. Dharan Cantonment - The Early Days? Journal of the Brigade of Gurkhas 1986; 216-217.

2. WAKELEY SIR JOHN. Report of the Hospital Recognition Committee. Royal College of Surgeons of England 1982.

3. RYAN J M. The Falklands War: Triage. Ann R Coll Surge 1984; 66: 195

4. STROWBridge N F and RYAN J M. Inappropriate Traditional Treatment Resulting in Limb Amputation R R Army Med Corps 1987; 133: 171-174.

\section{NOTICE TO ADVERTISERS}

Space orders should be sent to Combined Service Publications Ltd., P.O. Box 4, Farnborough, Hampshire GU14 7LR. Artwork and/or Copy should be forwarded to the same address to arrive by the first day of the month preceding issue, publication dates being February, June and October of each year.

Advertising Rates and Technical Details are as listed in British Rate and Data. 